\section{CHANGES OF MUSCULOSKELETAL SYMPTOMS, ERGONOMIC RISK, JOB STRESS, AND WORK INTENSITY OVER 12 YEARS IN A AUTOMOBILE COMPONENT FACTORY}

${ }^{1}$ BY Jang*, ${ }^{1,2}$ DM Kang, ${ }^{1,2}$ YK Kim, ${ }^{1}$ JE Kim. ${ }^{1}$ Dept. Occupational and Environmental Medicine, Pusan National University Yangsan Hospital, Yansan, Korea; ${ }^{2}$ Dept. Preventive and Occupational Medicine, Pusan National University School of Medicine, Yansan, Korea

\subsection{6/oemed-2018-ICOHabstracts.787}

Introduction The purpose of this study is to evaluate the relationship between musculoskeletal disorder (MSDs) symptoms and risk factors of MSDs in Korean automobile component manufacturers across times.

Methods This study has been tracking blue collar workers in a factory via 5 consecutive surveys from 2004 to 2016. A questionnaire survey was conducted on all of the blue collar workers at the target workplace. About $10 \%$ of the blue collar workers has been selected and asked to participate in field surveys. Ergonomic risk factors were subdivided into categories such as musculoskeletal burden, ANSI checklist, ACGIH TLV for Hand activity, RULA and etc. Job stress was estimated by Korean Occupational Stress Scale (KOSS). Work intensity was classified into three categories; absolute, relative work intensity and work flexibility.

Result The prevalence of MSDs according to criteria 1(P1) decreased from $89.3 \%$ in 2010 to $79.5 \%$ in 2016 . The prevalence of MSDs according to criteria 2, 3, and 4 (P2, P3, and P4) also decreased. Aspect of ergonomic risk factors, the longer the exposure time to musculoskeletal burdening work, the higher the prevalence of MSDs. First grade of ANSI checklist increased by time while those of 2 nd and $3 \mathrm{rd}$ decreased. Overall, ergonomic risk factor has generally declined because of working environment improvement. In workplace stress assessment, the high job stress group had increased until 2010 then had decreased since 2010. In subcategories of KOSS, physical environment were high in MSD symptom group. In work intensity survey, symptom positive group had consistently scored high in all absolute and relative work intensity and work flexibility. Whereas both absolute and relative work intensity decreased since 2010, work flexibility increased in 2016 from 2013.

Discussion This study shows the effects of multiple risk factors on MSD symptoms. In depth analysis considering repetitive measure of longitudinal data will be shown.

\section{WORK-RELATED RISK FACTORS FOR LUMBOSACRAL RADICULOPATHY: SYSTEMATIC REVIEW AND META- ANALYSIS}

\begin{abstract}
${ }^{1}$ PPaul FM Kuijer* ${ }^{2}$ Jos H Verbeek, ${ }^{3}$ Andreas Seidler, ${ }^{4}$ Rolf Ellegast, ${ }^{1,5}$ Carel TJ Hulshof, ${ }^{1}$ Monique HW Frings-Dresen, ${ }^{1}$ Henk F van der Molen. ${ }^{1}$ Academic Medical Centre, Coronel Institute of Occupational Health, Netherlands Centre for Occupational Diseases, Amsterdam, the Netherlands; ${ }^{2}$ Finnish Institute of Occupational Health, Kuopio, Finland; ${ }^{3}$ Medical Faculty Carl Gustav Carus, TU Dresden, Dresden, Germany; ${ }^{4}$ Institute for Occupational Safety and Health of the German Social Accident Insurance, Sankt Augustin, Germany; ${ }^{5}$ Netherlands Society of Occupational Medicine (NVAB), Centre of Excellence, Utrecht, the Netherlands
\end{abstract}

\subsection{6/oemed-2018-ICOHabstracts.788}

Introduction Clinicians need to know whether lumbosacral radiculopathy (LRS) can be attributed to work. Therefore the association between work-related risk factors and clinically assessed LRS has to be established.
Methods A systematic review was performed using Pubmed and Embase until March 2017. Inclusion criteria were that LRS was diagnosed by a clinician and exposed workers were compared to workers less or not exposed. A quality assessment and a meta-analysis were performed.

Result The search resulted in 7350 references and 24 studies fulfilled the inclusion criteria: 19 studies were rated as having a high risk of bias and five as having a low risk of bias. The median number of LRS participants per study were 209 (IQR 124-504). The meta-analysis revealed significant associations with heavy physically demanding work $(\mathrm{OR}=2.0,95 \% \mathrm{CI}: 1.5$ to 2.8), bending and/or twisting of the trunk $(\mathrm{OR}=2.4$, 95\% CI: 1.7 to 3.6 ), and lifting and carrying in combination with bending and/or twisting of the trunk $(\mathrm{OR}=2.8,95 \% \mathrm{CI}$ : 2.2 to 3.7). Professional driving and sitting were not significantly associated with LRS.

Discussion Evidence is available that LRS can be classified as a work-related disease depending on the level of exposure to bending of the trunk and/or lifting and carrying in physically demanding work. A policy to prevent LRS should focus on work-related risk factors since no other modifiable risk factors are known.

\section{CONSTRUCTION ERGONOMICS: A SUPPORT WORK MANUFACTURER'S PERCEPTIONS AND PRACTICES}

John Smallwood. Nelson Mandela Metropolitan University, Port Elizabeth, South Africa

\subsection{6/oemed-2018-ICOHabstracts.789}

Introduction Ergonomics hazards in construction include ergonomic stresses such as bending, lifting, and repetitive movement and vibration; environmental stresses such as heat, sun, noise, poor illumination, and wet or damp work; skin and respiratory exposure to chemicals and dust, as well as mental stress. In South Africa, these may add to the health problems experienced by construction workers because of poor community health, substance abuse, and inadequate health services. The erection and dismantling of support work are major activities on projects that entail a reinforced concrete structure, and present a range of ergonomics challenges.

Methods A self-administered questionnaire survey was conducted among staff of a support work manufacturer and supplier attending two workshops presented by the author to determine, inter alia, the importance of project parameters, and ergonomics during the six project stages, the frequency at which their organisation considers ergonomics relative to various occasions, and temporary works design related aspects, and the extent to which temporary works design related aspects impact on ergonomics.

Results Findings include: ergonomics is important in general, and during most of the seven project stages; ergonomics is considered relative to most occasions, especially during detailed design, and relative to most temporary works design related aspects, and there is a high level of awareness in terms of the extent to which temporary works design related aspects impact on ergonomics.

Discussion The findings indicate that there is a higher level of awareness regarding ergonomics among the sample stratum than the general built environment population, especially permanent works designers. However, the source of ergonomics knowledge is informal as opposed to formal, and the respondents' self-rating of their ergonomics, construction ergonomics, 